\title{
Influence of the Echocardiographic Score and Not of the Previous Surgical Mitral Commissurotomy on the Outcome of Percutaneous Mitral Balloon Valvuloplasty
}

\author{
Edison C. Sandoval Peixoto, Rodrigo T. Sandoval Peixoto, Ivana Picone Borges, Paulo Sérgio de 0 liveira, \\ Marta Labrunie, Mário Salles N etto, Ronaldo A. Villela, Pierre Labrunie, Guilherme A. Xavier de Brito, \\ Ricardo T. Sandoval Peixoto \\ Rio de Janeiro - Niterói, RJ - Brazil
}

\begin{abstract}
Objective - To evaluate prior mitral surgical commissurotomy and echocardiographic score influence on the outcomes and complications of percutaneous mitral balloon valvuloplasty.
\end{abstract}

Methods - We performed 459 complete mitral valvuloplasty procedures. Four hundred thirteen were primary valvuloplasty and 46 were in patients who had undergone prior surgical commissurotomy. The prior commissurotomy group was older, had higher echo scores, and a tendency toward a higher percentage of atrial fibrillation.

Results - When the groups were compared with each other, no differences were found in pre-and postprocedure mean pulmonary artery pressure, mean mitral gradient, mitral valve area, and mitral regurgitation. Because we found no significant differences, we subdivided the entire group based on echo scores, those with echo scores $\leq 8$ and those with echo scores $>8$ the mitral valve area being higher in the $\leq 8$ echo score group $2.06 \pm 0.42$ versus $1.90 \pm 0.40 \mathrm{~cm}^{2}$ $(p=0.0090)$ in the $>8$ echo score group.

Conclusion - Dividing the groups based on echo score revealed that the higher echo score group had smaller mitral valve areas postvalvuloplasty.

Keywords: percutaneous mitral balloon valvuloplasty, prior mitral commissurotomy, mitral stenosis.

Cinecor (IV Centenário e Pró-Cardíaco) Rio de Janeiro e Hospital Universitário Antônio Pedro - UFF, Niterói

Correspondência: Edison C. Sandoval Peixoto - Av. Epitácio Pessoa, 4986/301 - 22471-001 - Rio de Janeiro, RJ
In 1984 , Inoue at al. ${ }^{1}$ reported on the percutaneous mitral valve balloon dilatation technique, using the balloon subsequently named after Inoue.

We began percutaneous mitral balloon valvuloplasty in 1987 using a single balloon, and soon after we used the double balloon technique, Inoue's balloon technique, and the low profile single balloon technique ${ }^{2-5}$.

Percutaneous mitral balloon valvuloplasty has become the treatment of choice for symptomatic severe mitral stenosis without great damage to the subvalvular mitral apparel or great calcification or thickening of the mitral valve leaflets. It has had consistent results, and is currently preferred over surgical mitral commissurotomy in the type of patients mentioned above.

We have been using the Inoue balloon and single balloon techniques above all others ${ }^{2-5}$. We use the double balloon technique less frequently. The literature shows in general similar results with these techniques ${ }^{3-8}$.

We present here our experience with primary mitral balloon valvuloplasty compared with mitral balloon valvuloplasty following restenosis after surgical mitral commissurotomy, which we have been studying for some time ${ }^{9}$. The efficacy of percutaneous mitral balloon valvuloplasty for treating restenosis postsurgical mitral commissurotomy has been demonstrated by us and others.

\section{Methods}

Of 476 percutaneous mitral balloon valvuloplasty procedures performed between July 6, 1987 and December 31,1998 , we studied prospectively the outcomes of 459 procedures. The 413 patients who underwent primary balloon mitral valvuloplasty formed the primary valvuloplasty group. The first interventional treatment in this group was percutaneous mitral balloon valvuloplasty. The 46 patients who underwent mitral balloon valvuloplasty for 
restenosis after they have already undergone surgical commissurotomy formed the prior surgical commissurotomy group. Seventeen procedures were either not completed or had complications that impeded their performance, so were excluded from the study.

Of the 46 patients in the prior surgical commissurotomy group, 39 were female and 7 were male, but in the primary valvuloplasty group 339 were female and 74 were male $(\mathrm{p}=0.6486)$. No significant statistical difference existed.

Age in the prior surgical commissurotomy group was $42.7 \pm 12.4$ years and $36.9 \pm 12.5$ years in the primary valvuloplasty group $(\mathrm{p}=0.0030$ ), the prior surgical commissurotomy group being older.

Ten patients were in NYHA functional class II, 32 were in functional class III, and 4 were in functional class IV in the prior surgical commissurotomy group. In the primary valvuloplasty group, 6 patients were in functional class I, 91 were in functional class II, 272 were in functional class III, and 44 were in functional class IV ( $\mathrm{p}=0.8236)$, with no significant differences existing among the groups.

Heart rhythm was sinusal in 35 patients in the prior surgical commissurotomy group, and atrial fibrillation was present in 11 . In the primary valvuloplasty group, heart rhythm was sinusal in 358 , and atrial fibrillation was present in $55(\mathrm{p}=0.0520)$, with a tendency toward a greater percentage of atrial fibrillation in the prior surgical commissurotomy group.

Nine patients underwent mitral balloon valvuloplasty, developed restenosis during the follow-up period, and had to undergo a new mitral balloon valvuloplasty.

Echocardiographic mitral area determined by the half pressure time method before mitral balloon valvuloplasty was $1.00 \pm 0.22 \mathrm{~cm}^{2}$ in the prior surgical commissurotomy group and $0.94 \pm 0.21 \mathrm{~cm}^{2}$ in the primary valvuloplasty group, $(\mathrm{p}=0.0699)$. The echo score ${ }^{10}$ was $7.7 \pm 1.5$ points in the prior surgical commissurotomy group and 7.2 \pm 1.4 in the primary valvuloplasty group $(\mathrm{p}=0.0158)$. It was significantly higher in the prior surgical commissurotomy group.

We used Inoue's balloon in 65 procedures (maximum inflations of 24,26 , and $27 \mathrm{~mm}$ diameter were used once, $25 \mathrm{~mm}$ was used twice, and $28 \mathrm{~mm}$ was used 60 times), the low profile single balloon in 385 ( $25 \mathrm{~mm}$ was used 12 times, $25 \mathrm{~mm}$ followed by $30 \mathrm{~mm}$ was used 6 times and, finally, $30 \mathrm{~mm}$ alone was used 367), the conventional single balloon was used 3 times (20mm diameter), and the double balloon in $6(20+15 \mathrm{~mm}$ in 3 and $20+18 \mathrm{~mm}$ in 3 ), being a total of 459 procedures with those techniques.

After mitral dilation, left ventriculography in the right anterior oblique view was performed, in addition to new right and left catheterization and a new measure of the left atrium-left ventricle gradient. Measurement was always made of the simultaneous left atrium-left ventricle gradient immediately before and immediately after the dilation of the mitral valve. Early and middiastolic and presystolic gradients were measured, the mean gradient (method of the 3 points) being the arithmetic average of the 3 measures previously reported or, in a second phase, by the automatic planimetric area of the gradient ${ }^{11}$. Mitral valvular area was determined both pre- and postdilation. Cardiac output was determined by thermodilution and, the Gorlin and Gorlin formula ${ }^{12}$ was used to calculate the area. The presence of mitral insufficiency was graduated according to the semiquantitative criterion of Sellers et al. ${ }^{13}$.

The following parameters were studied: age, sex, rhythm, preprocedure NYHA functional class, mitral valve, echo score ${ }^{10}$, preprocedure echo mitral valve area, pre- and postballoon valvuloplasty mean pulmonary artery pressure, pre- and postprocedure mean mitral gradient, pre- and postprocedure hemodynamic measured mitral valve area, and pre- and postprocedure mitral regurgitation. The data obtained in the 2 groups were compared.

As pre- and postprocedure data studied revealed no significant statistical differences, the entire group of the 459 procedures performed was then subdivided into 2 new groups, the first one with echo scores $\leq 8$ and the second one with echo scores $>8$. We then looked again at pre- and postballoon valvuloplasty mean pulmonary artery pressure, pre- and postprocedure mean mitral gradient, and the preand postprocedure hemodynamically measured mitral valve area.

The statistical analysis was accomplished with the use of the program "EPI-INFO version 6" ${ }^{14}$ to determine the frequency of the qualitative and numeric variables. The numeric variables were also studied through the analysis of the variance and the qualitative variables with the chisquare test.

\section{Results}

Four hundred fifty-nine percutaneous mitral balloon valvuloplasty procedures were performed, 46 in patients with restenosis in the follow-up of previous surgical commissurotomy and 413 in intervention patients in whom percutaneous mitral balloon valvuloplasty was the only interventional treatment.

See Tables I and II for the hemodynamic data obtained before and after mitral balloon valvuloplasty in the prior surgical commissurotomy and primary mitral valvuloplasty groups. No significant statistical differences were found between the two groups.

Tables III and IV show the mitral competence observed both pre- and postpercutaneous mitral balloon valvuloplasty in the prior surgical commissurotomy and primary mitral valvuloplasty groups. Ten cases of serious mitral regurgitation occurred, 2 in the prior surgical commissurotomy group and 8 in the primary valvuloplasty group $(p=0.2048)$. No significant difference existed in the distribution of the serious mitral regurgitation pre- and postpercutaneous mitral balloon valvuloplasty.

As the hemodynamic data were not significantly different between the groups, the entire group of 459 procedures was then subdivided into two new groups based on echo scores, one group with echo scores $\leq 8$ and the other with echo scores $>8$. Tables $V$ and VI provide the 


\begin{tabular}{|c|c|c|c|}
\hline \multicolumn{4}{|c|}{$\begin{array}{l}\text { Table I - Comparison of hemodymanic data prepercutaneous } \\
\text { mitral balloon valvuloplasty in the prior surgical commissuroto- } \\
\text { my and primary mitral valvuloplasty groups }\end{array}$} \\
\hline & $\begin{array}{l}\text { Prior } \\
\text { Commissurotomy } \\
\mathrm{N}=46\end{array}$ & $\begin{array}{l}\text { Primary } \\
\text { Valvuloplasty } \\
\mathrm{n}=413\end{array}$ & $\mathrm{p}$ \\
\hline $\begin{array}{l}\text { Mean pulmonary pressure } \\
(\mathrm{mmHg})\end{array}$ & $\quad 37.6 \pm 14.4$ & $37.8 \pm 14.2$ & 0.9515 \\
\hline $\begin{array}{l}\text { Mean mitral gradient } \\
(\mathrm{mmHg})\end{array}$ & $18.3 \pm 6.9$ & $19.6 \pm 6.9$ & 0.2342 \\
\hline Mitral valve area $\left(\mathrm{cm}^{2}\right)$ & $0.93 \pm 0.19$ & $0.90 \pm 0.21$ & 0.4092 \\
\hline
\end{tabular}

\begin{tabular}{|c|c|c|c|}
\hline \multicolumn{4}{|c|}{$\begin{array}{l}\text { Table II - Comparison of hemodymanic data postpercutaneous } \\
\text { mitral balloon valvuloplasty in the prior surgical commissuro- } \\
\text { tomy and primary mitral valvuloplasty groups }\end{array}$} \\
\hline & $\begin{array}{c}\text { Prior } \\
\text { Commissurotomy } \\
\mathrm{n}=46\end{array}$ & $\begin{array}{l}\text { Primary } \\
\text { Valvuloplasty } \\
\mathrm{n}=413\end{array}$ & $\mathrm{p}$ \\
\hline $\begin{array}{l}\text { Mean pulmonary pressure } \\
(\mathrm{mmHg})\end{array}$ & $26.6 \pm 10.9$ & $26.8 \pm 10.2$ & 0.9062 \\
\hline $\begin{array}{l}\text { Mean mitral gradient } \\
(\mathrm{mmHg})\end{array}$ & $6.3 \pm 4.2$ & $5.4 \pm 3.5$ & 0.1492 \\
\hline Mitral valve area $\left(\mathrm{cm}^{2}\right)$ & $1.92 \pm 0.41$ & $2.04 \pm 0.42$ & 0.0801 \\
\hline
\end{tabular}

\begin{tabular}{|lcccc|}
\hline \multicolumn{4}{|c|}{$\begin{array}{c}\text { Table III - Mitral competence prepercutaneous mitral balloon } \\
\text { valvuloplasty in the prior surgical commissurotomy and of } \\
\text { primary mitral valvuloplasty groups }\end{array}$} \\
\hline $\begin{array}{l}\text { Mitral } \\
\text { Insufficiency }\end{array}$ & $\begin{array}{c}\text { Prior } \\
\text { commissurotomy } \\
\mathrm{n}=46\end{array}$ & $\begin{array}{c}\text { Primary } \\
\text { Valvuloplasty } \\
\mathrm{n}=413\end{array}$ & Total & $\mathrm{P}$ \\
\hline 0 & 41 & 352 & 393 & \\
+ & 5 & 60 & 65 & 0.7602 \\
+ & - & 1 & 1 & \\
Total & 46 & 413 & 459 & \\
\hline
\end{tabular}

hemodynamic data for both pre- and post percutaneous mitral balloon valvuloplasty in the two groups. The pre- and postprocudure data was not significantly statistically different. However, the mitral valve area in the postprocedure group was significantly smaller in the $>8$ echo score group.

\section{Discussion}

Introduced by Inoue ${ }^{1}$, percutaneous mitral valvulplasty quickly became one of the preferred treatments for severe mitral stenosis. It was reported in the beginning that mitral valve area after percutaneous mitral balloon valvuloplasty was larger when the double balloon technique was used rather than the conventional single balloon ${ }^{6,15}$. The efficiency and low level of complications with the Inoue balloon ${ }^{16,17}$ have also been reported. Although values obtained with the double balloon ${ }^{18}$ have been reported, the immediate results with the double balloon and the Inoue

\begin{tabular}{|c|c|c|c|c|}
\hline \multicolumn{5}{|c|}{$\begin{array}{l}\text { Table IV - Mitral competence postpercutaneous mitral balloon } \\
\text { valvuloplasty in the prior surgical commissurotomy and of } \\
\text { primary mitral valvuloplasty groups }\end{array}$} \\
\hline $\begin{array}{l}\text { Mitral } \\
\text { Insufficiency }\end{array}$ & $\begin{array}{c}\text { Prior } \\
\text { commissurotomy } \\
\mathrm{n}=46\end{array}$ & $\begin{array}{c}\text { Primary } \\
\text { Valvuloplasty } \\
\mathrm{n}=413\end{array}$ & Total & $\mathrm{p}$ \\
\hline 0 & 35 & 286 & 321 & \\
\hline+ & 6 & 91 & 97 & \\
\hline H & 3 & 28 & 31 & 0,2048 \\
\hline +++ & 2 & 4 & 6 & \\
\hline ++++ & 0 & 4 & 4 & \\
\hline Total & 46 & 413 & 459 & \\
\hline
\end{tabular}

balloon are similar ${ }^{19}$. Today, it has been proven that similar mitral valve area after percutaneous mitral valvuloplasty can be obtained with any of the balloon techniques whether the double balloon, Inoue balloon, or low profile single balloon are used if effective balloon dilation areas are comparable ${ }^{3-5}$. The most recent studies ${ }^{4,15}$ have shown that average mitral valve area equal to or greater than $2 \mathrm{~cm}^{2} \mathrm{can}$ result in spite of the technique used ${ }^{4,15}$.

The incidence of mitral regurgitation is smaller when the balloon dilation area is corrected for the surface corporal area, being less than or equal to $4.0 \mathrm{~cm}^{220}$. According to Roch et al. ${ }^{21}$, the only variable that can predict an increase in mitral regurgitation is the relationship between the effective balloon dilation area and the surface corporal area. Aurora et al. ${ }^{22}$ showed that the size of the balloon, the degree of compromise of the subvalvar apparel, or the gravity of the mitral stenosis is not related to the appearance of mitral regurgitation. In spite of the high effective balloon dilation area that we used along with our experience, our incidence of significant mitral regurgitation was low ${ }^{2-5}$.

It has been shown that percutaneous mitral valvuloplasty can be accomplished with the same efficiency or at least with good results in groups of patients who undergo the procedure for either postsurgical mitral commissurotomy restenosis ${ }^{9,23-25}$ or postpercutaneous mitral valvuloplasty restenosis ${ }^{26}$.

In the present study, we evaluated the results obtained in a group of patients who underwent percutaneous mitral balloon valvuloplasty as the only treatment (primary valvuloplasty) in comparison with the results obtained in a group of patients who underwent percutaneous mitral balloon valvuloplasty for postsurgical mitral commissurotomy restenosis. The postsurgical mitral commissurotomy restenosis group was older, had higher echocardiographic scores, and had a tendency toward a higher percentage of atrial fibrillation and a larger mitral valve area before percutaneous mitral balloon valvuloplasty. Higher echocardiographic scores in this group of patients have been found also by others ${ }^{27}$.

The results obtained in the 2 groups for mean pulmonary pressure, mean mitral gradient, and mitral valve area before percutaneous mitral balloon valvuloplasty were not significantly different, nor did a significant difference exist after percutaneous mitral balloon valvuloplasty. However, 
in spite of no significant difference existing, a tendency was noted toward smaller mitral valve areas in the postsurgical mitral commissurotomy restenosis group, $1.92 \pm 0.41 \mathrm{~cm}^{2}$ versus $2.04 \pm 0.42 \mathrm{~cm}^{2}(\mathrm{p}=0.0801)$, in the primary mitral valvuloplasty group (tables I and II).

Lee et al. ${ }^{23}$ also found a smaller increase in the mitral valve area postpercutaneous mitral balloon valvuloplasty in their postsurgical mitral commissurotomy restenosis group, but the difference was also not significant. In a subsequent report, Lau et al. ${ }^{25}$, of the same group, reported mitral gradient, mitral valve area, mitral insufficiency, and restenosis in the follow-up similar to that in the postsurgical mitral commissurotomy restenosis group and in the primary mitral valvuloplasty group. Although both authors reported smaller valvular areas after percutaneous mitral balloon valvuloplasty $\left(1.6 \mathrm{~cm}^{2}\right)$ than we did. Sharma et al. ${ }^{27}$ and Medina et al. ${ }^{28}$ found similar results in their 2 groups of patients for hemodynamic data and for mitral insufficiency, although the postsurgical mitral commissurotomy restenosis group of Sharma et al. ${ }^{27}$ had higher echocardiographic score.

Like the last authors mentioned above, we also did not find a difference in the presence of mitral insufficiency either before percutaneous mitral balloon valvuloplasty mitral insufficiency (table III) or after percutaneous mitral balloon valvuloplasty (table IV) in the 2 study groups. Results very similar to ours were reported by Ha et al. ${ }^{29}$, who obtained larger values for mitral gradient and smaller for mitral valve area, both without statistical differences, and similar variations for mitral insufficiency.

The differences that we obtained were not significant. The importance of the Wilkins et al. ${ }^{10}$ echocardiographic scores is demonstrated in the results obtained in percutaneous mitral balloon valvuloplasty ${ }^{30}$. Because our percutaneous mitral balloon valvuloplasty postsurgical mitral commissurotomy group had higher echo scores than the primary percutaneous mitral balloon valvuloplasty group, $7.7 \pm 1.5$ versus $7.2 \pm 1.4$ points $(\mathrm{p}=0.0158)$ and a tendency toward slightly better results in the primary percutaneous mitral balloon valvuloplasty group, we redivided the total 459 procedures into a patient group with echo scores $\leq 8$ and a patient group with echo scores $>8$ to better study the influence of echocardiographic scores on the obtained results. The new groups did not have significant differences for mean pulmonary pressure, mean mitral gradient, and mitral valve

\begin{tabular}{|c|c|c|c|}
\hline \multicolumn{4}{|c|}{$\begin{array}{l}\text { Table } \mathrm{V} \text { - Comparison of hemodymanic data prepercutaneous } \\
\text { mitral balloon valvuloplasty in the groups with echocardiographic } \\
\text { scores of } \leq 8 \text { and }>8\end{array}$} \\
\hline & $\begin{array}{l}\text { Echo score } \\
\quad \leq 8 \\
\mathrm{n}=393\end{array}$ & $\begin{array}{c}\text { Echo score } \\
\begin{aligned} & >8 \\
n & =66\end{aligned}\end{array}$ & $\mathrm{P}$ \\
\hline $\begin{array}{l}\text { Mean pulmonary pressure } \\
(\mathrm{mmHg})\end{array}$ & $37.5 \pm 13.9$ & $39.3 \pm 16.6$ & 0.4041 \\
\hline $\begin{array}{l}\text { Mean mitral gradient } \\
(\mathrm{mmHg})\end{array}$ & $19.7 \pm 6.8$ & $18.3 \pm 7.3$ & 0.1753 \\
\hline Mitral valve area $\left(\mathrm{cm}^{2}\right)$ & $0.90 \pm 0.21$ & $0.94 \pm 0.20$ & 0.1164 \\
\hline
\end{tabular}

\begin{tabular}{|c|c|c|c|}
\hline \multicolumn{4}{|c|}{$\begin{array}{l}\text { Table VI - Comparison of hemodymanic data postpercutaneous } \\
\text { mitral balloon valvuloplasty in the groups with echocardiographic } \\
\text { scores of } \leq 8 \text { and }>8\end{array}$} \\
\hline & $\begin{array}{l}\text { Echo score } \\
\quad \leq 8 \\
n=393\end{array}$ & $\begin{array}{l}\text { Echo score } \\
\begin{aligned} & >8 \\
n & =66\end{aligned}\end{array}$ & $P$ \\
\hline $\begin{array}{l}\text { Mean pulmonary pressure } \\
(\mathrm{mmHg})\end{array}$ & $26.7 \pm 10.1$ & $28.0 \pm 10.6$ & 0.3730 \\
\hline $\begin{array}{l}\text { Mean mitral gradient } \\
(\mathrm{mmHg})\end{array}$ & $5.5 \pm 3.6$ & $5.5 \pm 3.3$ & 0.9629 \\
\hline Mitral valve area $\left(\mathrm{cm}^{2}\right)$ & $2.06 \pm 0.42$ & $1.90 \pm 0.40$ & 0.0090 \\
\hline
\end{tabular}

area in the prepercutaneous mitral balloon valvuloplasty results (table V), or for mean pulmonary artery pressure and mean mitral gradient in the postpercutaneous mitral balloon valvuloplasty results (table VI). However, mitral valve area postpercutaneous mitral balloon valvuloplasty was significantly smaller in the group with scores $>8$ when compared with the mitral valve area obtained in the group with scores $\leq 8$, respectively, $1.90 \pm 0.40$ versus $2.06 \pm 0.42 \mathrm{~cm}^{2}$ $(\mathrm{p}=0.0090)$, (table VI).

Jang et al. ${ }^{31}$ also demonstrated the importance of the echocardiographic score when they showed worse immediate results and in the follow-up of their postsurgical mitral commissurotomy group; however, they redivided this group into two subgroups with scores $\leq 8$ and scores $>8$. The subgroup with the score $\leq 8$ had results and evolution similar to that in the primary valvuloplasty group.

We conclude that mitral balloon valvuloplasty is an effective treatment for severe mitral stenosis secondary to postsurgical mitral commissurotomy restenosis, similar statistical results being present in the 2 study groups. A tendency existed toward a slightly smaller mitral area in the postsurgical mitral commissurotomy group, influenced by a higher echocardiographic score in this group. 


\section{References}

1. Inoue K, Owki T, Kikamara T, Kitamura F, Miyamoto M. Clinical application of transvenous mitral commissurotomy by a new balloon catheter. J Thorac Cardiovasc Surg 1984; 87: 394-402.

2. Peixoto ECS, Oliveira PS, Salles Netto M, et al. Valvoplastia mitral percutânea por balão. Resultados imediatos, complicações e evolução hospitalar. Arq Bras Cardiol 1995; 64: 109-16.

3. Peixoto ECS, Oliveira PS, Salles Netto M, et al. Valvoplastia mitral percutânea com a técnica do balão único. Resultados imediatos, complicações e evolução intra-hospitalar. Arq Bras Cardiol 1996; 66: 267-73.

4. Peixoto ECS, Oliveira PS, Salles Netto M, et al. Balão único versus balão de Inoue na valvoplastia mitral percutânea por balão. Resultados imediatos e complicações. Arq Bras Cardiol 1998; 71: 59-64.

5. Peixoto ECS, Oliveira PS, Salles Netto M, et al. Comparação dos resultados e complicações das técnicas do balão único e do balão de Inoue na valvoplastia mitral percutânea por balão. Rev Bras Cardiol Invas 1998; 6: 6-12

6. Chen CR, Huang ZD, Lo ZX, Cheng TO. Comparison of single rubber nylon balloon and double polyethylene balloon valvoplasty in 94 patients with rheumatic mitral stenosis. Am Heart J 1990; 119: 102-11.

7. Patel J, Vylhilingum S, Mitha AS. Balloon dilatation of the mitral valve by a single, bifoil ( 2 x 19mm) or trifoil (3 x 15mm) catheter. Br Heart J 1990; 64: 342-6.

8. Ribeiro PA, Fawzy ME, Arafat MA, et al. Comparison of mitral valve area results of balloon mitral valvotomy using the Inoue and double balloon techniques. Am J Cardiol 1991; 68: 687-8.

9. Peixoto ECS, Burello DM, Borges IP, et al: Prior mitral comissurotomy and echocardiographic score influence in mitral balloon valvuloplasty. Am J Cardiol 1999, 84(supl 6A): 122P-123P.

10. Wilkins GT, Weyman AE, Abascal VM, Block PC, Palacios IF. Percutaneous mitral valvotomy: An analysis of echocardiographic variables related to outcome and the mechanism of dilatation. Br Heart J 1988; 60: 299-308.

11. Yang SS, Bentivoglio L, Maranhão V, Golberg H. From cardiac catherization data to hemodynamic parameters. F A Davis Company, 2nd. Edition, Philadelphia 1978, p.1-54.

12. Gorlin R, Gorlin SG. Hydraulic formula for calculation of the area of the stenotic mitral valve, other cardiac values and central circulatory shunts. Am Heart J 1951, 41: 1-29.

13. Sellers RD, Levy MJ, Amplatz K, Lillehei CW. Left retrogade cardioangiography in acquired cardiac disease. Technic, indication and interpretations in 700 cases. Am J Cardiol 1964; 14: 437-47.

14. Dean AG, Dean JA, Coulombier D, et al. Epi-Info, version 6: A word processing, database and statistic program for public health on IBM-microcomputers. The division of surveillance and epidemiology. Epidemiology program office. Centers for disease control and prevention, Atlanta, 1995.

15. Waller BF, Vantassel JW, McKay C. Anatomic basis for and morfologic results from catheter balloon valvoplasty of stenotic mitral valves. Clin Cardiol 1990; 13; 655-61.
16. Nishimura RA, Holmes Jr J, Rucler GS. Eficacy of percutaneous mitral balloon valvuloplasty with the Inoue balloon. Mayo Clin Proc 1991; 66: 276-82.

17. Feldman T, Carroll JD. Valve deformity and balloon mechanics in percutaneous transvenous mitral commissurotomy. Am Heart J 1991; 121: 1628-33.

18. Farhat MB, Belbout F, Gamra H, et al. Results of percutaneous double-balloon mitral commissurotomy in one medical center in Tunisia. Am J Cardiol 1995; 76 : 1266-70.

19. Cardoso LF, Grinberg M, Patrício M, et al. Estudo comparativo entre balão único de Inoue e duplo balão na valvoplastia mitral percutânea. Resultados imediatos e após seguimento de um ano. Arq Bras Cardiol 1996; 66: 213-6.

20. Abascal VW, Wilkins GT, Choong CY, Block PC, Palacios IF, Weyman AE. Mitral regurgitation after percutaneous balloon mitral valvuloplasty in adults: Evaluation by pulsed doppler echocardiography. J Am Coll Cardiol 1988; 11: 257-63.

21. Roth RB, Block PC, Palacios IF. Predictor of increased mitral regurgitation after mitral balloon valvotomy. Cathet Cardiovas Diagm 1990; 20: 17-21.

22. Aurora R, Nair M, Kaha GS, et al. Non surgical mitral valvuloplasty for rheumatic mitral stenosis. Indian Heart J 1990; 42: 329-34.

23. Lee CY, Lau KW, Ding ZP, et al. Percutaneous balloon valvuloplasty in mitral restenosis after previous surgical commissurotomy. Singapore Med J 1995; 36 : 474-8.

24. Rediker DE, Block PC, Abascal VM, Palacios IF. Mitral balloon valvuloplasty for mitral restenosis after surgical commissurotomy. J Am Coll Cardiol 1988; 11 : $252-6$

25. Lau KW, Ding ZP, Gao W, Koh TH, Johan A. Percutaneous balloon mitral valvuloplasty in patients with mitral restenosis after previous surgical commissurotomy. A matched comparative study. Eur Heart J 1996; 17: 1367-72.

26. Pathan AZ, Mahdi NA, Leon MN, et al. Is redo percutaneous mitral balloon valvuloplasty (PMV) indicated in patients with post-PMV mitral restenosis? J Am Coll Cardiol 1999; 34: 49-54

27. Sharma S, Loya YS, Desai DM, Pinto RJ. Balloon valvotomy for mitral restenosis after open or closed surgical commissurotomy. Int J Cardiol 1993; 39: 103-8.

28. Medina A, Lezo JS, Hernandez E, et al. Balloon valvuloplasty for mitral restenosis after previous surgery: a comparative study. Am Heart J 1990; 120: 568-71.

29. Ha JW, Shim WH, Yoon JH, et al. Percutaneous mitral balloon valvuloplasty in patients with restenosis after surgical commissurotomy: a comparative study. Yonsei Med J 1993; 34: 243-7.

30. Palacios IF, Tuzcu ME, Weyman AE, Newell JB, Block PC. Clinical follow-up of patients undergoing percutaneous mitral balloon valvotomy. Circulation 1995; 91: 671-6.

31. Jang IK, Block PC, Newell JB, Tuzcu EM, Palacios IF. Percutaneous mitral balloon valvotomy for recurrent mitral stenosis after surgical commissurotomy. Am J Cardiol 1995; 75: 601-5. 